the borderlines between geology and physics, or geology and chemistry. Advances in such fields as geophysics call for workers with more extensive training in the two subjects. The ca operation of geophysicist and geologist makes possible the interpretation of concealed structures: England south from the Wash requires special study in view of the possibilities of new coalfields. But on a wider front we may expect to learn more of submarine areas, of the structure and origin of mountains and of the larger features of the earth. Work in geochemistry, in the distribution of minerals, the origin of rocks and the nature of clays, promizes rapid development. In the fields of geomorphology the problems are barely touched; in palæontology the existing data only serve to illustrate the extent of the problems to be solved. But in all these extensions of knowledge it may be hoped that it will be possible to avoid the isolation of the fields of study, relating them all to stratigraphy and the study of the structure of the earth's crust which form the 'heart of geology'.

\section{TEACHING ZOOLOGY IN THE UNIVERSITY}

$\mathrm{P}$

ROF. H. GRAHAM CANNON discusses "Under. graduate Zoology" in his presidential address to Section D (Zoology). After the First World War, he says, the interest in zoology became almost exclusively experimental. The more orthodox attitude of comparative anatomy became the one to be avoided. This was due to a variety of reasons, but largely because, for generations, zoologists had been teaching the comparative anatomy of dead animals without worrying about how these animals lived. As a result of this changed outlook between the two World Wars, a generation of teachers has grown up who are predominantly experimentalists, and our present undergraduates run the risk of becoming very knowledgeable about the latest developments of experimental technique while knowing very little indeed about the anatomy of the animals on which they work. Recently, but somewhat tardily, it has become recognized that there is such an aspect of zoology as functional morphology, that is, a method of treatment where suructures are dealt with not merely in the way in which they are built, but also, and at the same time, from the way in which they function. It is this attitude which should form the basis of undergraduate zoology.

Two main difficulties present themselves in considering the teaching of zoology to undergraduates. First, there is the modern tendency to scorn any elementary teaching and to thrust the first year's university work back on to the schools. This misguided attitude may be excusable in the more basic physical sciences and mathematics: but in the biological sciences, which, after all, utilize the physical sciences as their tools, it is completely illogical. Moreover, it is essential that the more experienced teachers, preferably the professor, should always deal with this fundamental first year's introduction to university study.

- Secondly, there is the tendency almost everywhere to introduce specialist courses into the undergraduate years : a tendency which is being encouraged by the efforts of the University Grants Committee to foster the establishment of readerships or even chairs in the most abstruse specialist aspects of biology. At the undergraduate stage the students are quite unable to assimilate such courses. The sort of courses which are being established are those admirably suited for the second part of the Cambridge Tripos. But what is almost invariably overlooked is that the second part is entirely a postgraduate course. The honours degree is given on the first part of the Tripos, and this corresponds to the degrees in the 'Redbrick Universities' of honours general science. It is suggested that it would be a great advantage in all 'Redbrick Univer. sities' to abolish the specialist honours degree altogether and insist on a first degree being taken in general science as at Cambridge. The more specialist attitude to the subject could then be left to a postgraduate year, leading preferably to a master's degree.

\section{SOCIAL GEOGRAPHY}

$I^{\mathrm{N}}$ $\mathrm{T}$ his presidential address to Section E (Geography), Lord Rennell of Rodd deals with the geographical environment of man as a social animal, and con. sequently does not attempt to consider the geographical circumstances of the origin of human species or prehistoric man. But the spiritual as well as the material consequences of geography on human society are considered rather by posing a series of questions, and stating a number of problems, especially in connexion with Africa, than by proposing conclusions or solutions.

Starting from the influence of geography on the spiritual as well as on the material development of society, Lord Rennell makes a strong plea, which he takes up again at the end of the address, for the teaching of geography in medium and higher education as a means of creating a bridge between the humanities and the natural sciences, which "except among the leaders of the latter group" have more and more tended to develop on independent lines divorced from each other. This tendency he dates from the decline in classical education; but he sees in geography, and especially in social geography, a new link which could be made between the two, in view of the manifold contacts which geography has with both the exact and the abstract realms of human thought.

From this point he goes on to discuss a number of problems arising in Africa. What are the reasons why Islam spread as far as the southern rim of the North African deserts but never affected the popu. lation south of the northern fringe of the forest belt ? Why was the negro and negroid population of Africa antagonistic to outside civilization in spite of many opportunities of contact with more civilized people from Greek and Carthaginian times through all the period of Arab and Portuguese navigation until the European conquest? Why then, and only then, did a ferment of Western civilization begin, within say the last seventy years? Yet the civilizing influence of the Mediterranean found no difficulty in crossing the Sahara and following up the Niles until they came to a dead end against the unwillingness of the negro to adopt or adapt. Why is there no trace of writing or even ideography in Dark Africa? Why was there no true architecture, the wheel or the plough in Africa south of the deserts until the conquering European started the modern phase?

Lord Rennell goes on to discuss the anomalous and absurd consequences of the European conquest, the purpose of which, in spite of Lord Hailey's investigations, remains very obscure. He refers to 